\title{
Inhibitory effect of tumor necrosis factor- $\alpha$ on the basolateral Kir4.1/Kir5.1 channels in the thick ascending limb during diabetes
}

\author{
GUOYAN ZHANG $^{1 *}$, ZHIMING LV $^{1 *}$, YANG ZHAO $^{2}$, RUI CHEN $^{2}$, \\ XIANGYU ZHAN ${ }^{2}$, WEIQUN WANG ${ }^{2}$ and HONGYU SUI ${ }^{2}$ \\ ${ }^{1}$ Department of Urology and Endocrinology, First Affiliated Hospital, Jiamusi University, Jiamusi, Heilongjiang 154003; \\ ${ }^{2}$ Department of Physiology, Basic Medical College, Jiamusi University, Jiamusi, Heilongjiang 154007, P.R. China
}

Received April 30, 2021; Accepted August 13, 2021

DOI: $10.3892 / \mathrm{etm} .2021 .10677$

\begin{abstract}
Diabetic nephropathy is a major contributor to the morbidity and mortality of patients with diabetes. TNF- $\alpha$ expression is elevated during diabetes and is implicated in the pathogenesis of diabetic nephropathy; however, its underlying molecular mechanisms remain unclear. The present study aimed to investigate the effect and molecular mechanism of TNF- $\alpha$ on the basolateral inwardly rectifying potassium (Kir)4.1/Kir5.1 channels in the thick ascending limb (TAL) of rat kidneys using western blotting and the patch clamp technique to provide a theoretical basis for the cause of the decrease in kidney concentrating capacity during diabetes. The results demonstrated that urinary TNF- $\alpha$ excretion and protein TNF- $\alpha$ expression in the TAL increased and basolateral Kir4.1/Kir5.1 channel activity decreased during diabetes; however, diabetic rats exhibited amelioration of Kir4.1/Kir5.1 activity with a soluble TNF- $\alpha$ antagonist, TNF receptor fusion protein (TNFR:Fc). These results suggested that TNF- $\alpha$ inhibited the activity of the basolateral Kir4.1/Kir5.1 channel in the TAL of rat kidneys during diabetes. In addition, the protein expression levels of phospholipase $\mathrm{A}_{2}\left(\mathrm{PLA}_{2}\right)$ and cyclooxygenase- $-_{2}\left(\mathrm{COX}_{2}\right)$ increased in diabetic rats, the effects of which deceased following treatment with TNFR:Fc compared with the diabetic group. Furthermore, an agonist of $\mathrm{PLA}_{2}$ (melittin) and $\mathrm{COX}_{2}$ production [prostaglandin $\mathrm{E}_{2}\left(\mathrm{PGE}_{2}\right)$ ] inhibited the basolateral Kir4.1/Kir5.1 channels. Taken together, the results of the present study suggested that the inhibitory effect of TNF- $\alpha$ on the basolateral Kir4.1/Kir5.1 channels in the
\end{abstract}

Correspondence to: Professor Hongyu Sui, Department of Physiology, Basic Medical College, Jiamusi University, 148 Xuefu Street, Jiamusi, Heilongjiang 154007, P.R. China

E-mail: suihongyuhappy@163.com

*Contributed equally

Key words: tumor necrosis factor- $\alpha$, basolateral, inwardly rectifying potassium 4.1/inwardly rectifying potassium 5.1 channels, thick ascending limb, diabetes
TAL during diabetes is mediated by the $\mathrm{PLA}_{2} / \mathrm{COX}_{2} / \mathrm{PGE}_{2}$ signaling pathway.

\section{Introduction}

Diabetes mellitus is a group of metabolic diseases characterized by chronic hyperglycemia from defective insulin secretion and/or impaired biological effects (1). Diabetic nephropathy (DN) is a major microvascular complication of diabetes mellitus and the leading cause of end-stage renal disease, thereby contributing to the high mortality rates (2).

Several mechanisms contribute to the onset and development of DN, including hemodynamic factors, oxidative stress and cytokine signaling $(3,4)$. Recently, increasing evidence has suggested that inflammation plays a key role in the pathogenesis of DN, although it is commonly considered a non-inflammatory disease $(5,6)$. TNF- $\alpha$, a potent proinflammatory cytokine, is synthesized and released by infiltrating macrophages and intrinsic kidney cells (7). Previous studies have reported that increased urinary TNF- $\alpha$, as a pathogenic factor, may precede the appearance of pathological albuminuria, and thus is considered a marker of kidney injury in early stages of DN $(8,9)$. Several alterations in renal function occur during the initial stages of DN, including a decrease in urinary concentrating ability; however, its molecular mechanism remains unclear.

The thick ascending limb (TAL) of the Henle's loop is responsible for the reabsorption of $20-25 \%$ of filtered $\mathrm{NaCl}$, which is the most important step required to establish the hyperosmotic gradient of the medulla for the concentration of urine $(10,11)$. The basolateral $\mathrm{K}^{+}$channels in the TAL play a critical role in sustaining the transepithelial membrane transport by generating the cell membrane potential to drive $\mathrm{Cl}^{-}$diffusion $(12,13)$. Previous studies have demonstrated that the basolateral Kir4.1/Kir5.1 heterotetramers, with a conductance of 40-50 pS, are the predominant subtype in the $\mathrm{TAL}$, and indirectly influence the tubular $\mathrm{NaCl}$ transportation by regulating the activity of $\mathrm{Na}^{+}-\mathrm{K}^{+}-2 \mathrm{Cl}^{-}$cotransporters (NKCC2), which further affects urinary concentrating $(14,15)$. The main effects of impaired urinary concentrating ability in the kidney include renal polyuria, or even renal diabetes insipidus, and infection with the loss of immune substances in the urine. 
The present study aimed to investigate the effect of TNF- $\alpha$ on the basolateral Kir4.1/Kir5.1 channels in the TAL during diabetes. Furthermore, the study sought to determine its underlying regulatory mechanism to provide a theoretical basis for the detection of impaired kidney concentrating capacity during diabetes.

\section{Materials and methods}

Reagents. Antibodies against TNF- $\alpha$ (ab6671), phospholipase $\mathrm{A}_{2}\left(\mathrm{PLA}_{2}, \mathrm{AF6329}\right), \mathrm{COX}_{2}$ (AF7003), Kir4.1 (DF9260) and Kir5.1 (K009361P) were purchased from Abcam, Affinity and Solarbio. Melittin, prostaglandin $\mathrm{E}_{2}\left(\mathrm{PGE}_{2}\right)$, polylysine and collagenase were purchased from Sigma-Aldrich; Merck KGaA. TNF receptor fusion protein (TNFR:Fc) was purchased from CPGJ Pharmaceutical Co., Ltd. (http://27919267.b2b.11467.com/). The TNF- $\alpha$ (900TM73) and $\mathrm{PGE}_{2}$ ELISA kits (EK7124) were purchased from PeproTech, Inc., and Boster Biological Technology, respectively. The rat albumin ELISA kit (ab23564) was purchased from Abcam.

Animals and experimental design. Male pathogen-free Sprague-Dawley rats (weight, 200 \pm 20 g, 6-7 weeks old) were obtained from the Animal Facility of Jiamusi University, and housed at $20-25^{\circ} \mathrm{C}, 50-65 \%$ relative humidity and with a $12-\mathrm{h}$ light/dark cycle, with free access to normal food and water. A total of 40 rats were randomly divided into four groups: Control rats, diabetic rats, control rats treated with TNFR:Fc (control + TNFR:Fc) and diabetic rats treated with TNFR:Fc (diabetic + TNFR:Fc). Diabetic rats were induced via intraperitoneal injection of $60 \mathrm{mg} / \mathrm{kg}$ streptozotocin (STZ) dissolved in citric acid buffer. The levels of fasting blood glucose were monitored by drawing blood from the tail vein $72 \mathrm{~h}$ after STZ injection. The rats with fasting blood glucose $>16.7 \mathrm{mmol} / \mathrm{l}$ and increased drinking water, eating and urine volume were considered to be successful diabetic models. Subcutaneous injection of TNFR:Fc ( $2 \mathrm{mg} / \mathrm{kg})$ was performed twice a week in the control and diabetic rats before STZ injection for 3 weeks (16). All animal experiments were approved by the Medical Ethics Committee of Jiamusi University (Jiamusi, China; approval no. JMSU-229).

Measurement of urine output and urinary albumin. Rats were placed in metabolic cages to collect urine from 9 am to 9 am the next day, and the supernatant of urine following centrifugation was the $24 \mathrm{~h}$ urine output. Urinary albumin (UAlb) was measured using the ELISA kit for rat albumin, according to the manufacturer's instructions.

Measurement of TNF- $\alpha$ in urine and $P G E_{2}$ in tissues. The levels of TNF- $\alpha$ in urine and $\mathrm{PGE}_{2}$ in tissues were measured using the TNF- $\alpha$ rat ELISA and $\mathrm{PGE}_{2}$ rat ELISA kits, respectively, according to the manufacturer's instructions. Briefly, the standard solution and samples were added to the wells and the plates were incubated at $37^{\circ} \mathrm{C}$ for $90 \mathrm{~min}$. After washing three times with washing buffer, the plates were incubated with corresponding antibody working liquid for $60 \mathrm{~min}$ at room temperature. Subsequently, the plates were re-washed and incubated with $\mathrm{ABC}$ working solution at $37^{\circ} \mathrm{C}$ for $30 \mathrm{~min}$. Following addition of the TMB substrate, the plates were incubated for $10 \mathrm{~min}$ at $37^{\circ} \mathrm{C}$ in the dark. Absorbance was measured at a wavelength of $450 \mathrm{~nm}$, using a spectrophotometer (BioTek Instruments, Inc.), after adding the stop solution. The levels of TNF- $\alpha$ and $\mathrm{PGE}_{2}$ were quantified according to the standard curve.

Preparation of the TAL tissues. Rats were anesthetized using pentobarbital $(50 \mathrm{mg} / \mathrm{kg})$ and sacrificed via cervical dislocation. The kidneys were immediately removed and cut into 1-mm-thick sections after removing the capsule and poles. The renal cortex and inner stripe of outer medulla were carefully excised and minced with a blade under a dissecting microscope. Samples were incubated and shaken in HEPES buffer solution containing $10 \mathrm{mM}$ HEPES, $140 \mathrm{mM} \mathrm{NaCl}, 5 \mathrm{mM} \mathrm{KCl}, 1.5 \mathrm{mM} \mathrm{MgCl}_{2}$ and $1.8 \mathrm{mM} \mathrm{CaCl}_{2}$ (pH 7.4), with collagenase type $1 \mathrm{~A}(1 \mathrm{mg} / \mathrm{ml})$ at $37^{\circ} \mathrm{C}$ for $5 \mathrm{~min}$. Undigested tissues were subjected to three treatments with collagenase (5 min each) and the supernatants were combined. The combined supernatants were subsequently filtered through 180 and $50 \mu \mathrm{m}$ nylon mesh membranes, and the TALs retained on the $50 \mu \mathrm{m}$ mesh were collected for western blotting.

Western blotting. Protein samples $(30 \mu \mathrm{g})$ were extracted from the TAL tissues using RIPA lysis buffer, separated via 10 or $12 \%$ SDS-PAGE and transferred onto PVDF membranes. The membranes were blocked with blocking solution containing 5\% non-fat milk in TBS-0.05\% Tween (TBS-T) for $1 \mathrm{~h}$ at room temperature and subsequently incubated with the corresponding primary antibody at $4^{\circ} \mathrm{C}$ for $12 \mathrm{~h}$. Membranes were washed four times with TBS-T (15 min each) and subsequently incubated with the secondary antibody (ZB-2301; OriGene Technologies, Inc.) solution containing $5 \%$ non-fat dry milk in TBS-T for $1 \mathrm{~h}$ at room temperature, prior to re-washing with TBS-T (4x15 min). Protein bands were visualized using ECL plus chemiluminescence (Pierce; Thermo Fisher Scientific, Inc.) and analyzed using ImageJ software (version 1.45s; National Institutes of Health).

Patch clamp technique. The 1-mm-thick sections were incubated in HEPES buffer with collagenase type $1 \mathrm{~A}$ at $37^{\circ} \mathrm{C}$ for 40-60 $\mathrm{min}$. The digested TALs were isolated under a dissecting microscope and placed on a cover glass $(5 \times 5 \mathrm{~mm})$ coated with polylysine. The cover glass with TALs was transferred to a chamber filled with HEPES-buffered $\mathrm{NaCl}$ solution (in mM: $140 \mathrm{NaCl}, 5 \mathrm{KCl}, 1.5 \mathrm{MgCl}_{2}, 1.8 \mathrm{CaCl}_{2}$ and 10 HEPES, pH 7.4) and mounted on an inverted microscope (Nikon Corporation). Using a P-97 electrode-puller, the patch clamp electrodes were filled with a pipette solution (in mM: $10 \mathrm{HEPES}, 140 \mathrm{KCl}$ and $1.8 \mathrm{MgCl}_{2}, \mathrm{pH} 7.4$ ) and fixed to the probe to patch the treated TALs. The channel currents were low-pass filtered at $0.5 \mathrm{kHz}$ and recorded using an Axon 700B patch clamp amplifier. The data were digitized with an Axon interface (Digidata 1400A) and analyzed using pClamp 10.0 software (Axon Instruments; Molecular Devices, LLC). The channel activity, expressed as a product of channel number and open probability (NPo), was calculated from data samples of $90 \mathrm{sec}$ durations at a steady state, as follows: $N P_{\mathrm{O}}=\Sigma\left(1 t_{1}+2 t_{2}+\ldots \mathrm{i} t_{\mathrm{i}}\right)$, in which $t_{\mathrm{i}}$ is the fractional open time spent at each of the observed current levels. 
A

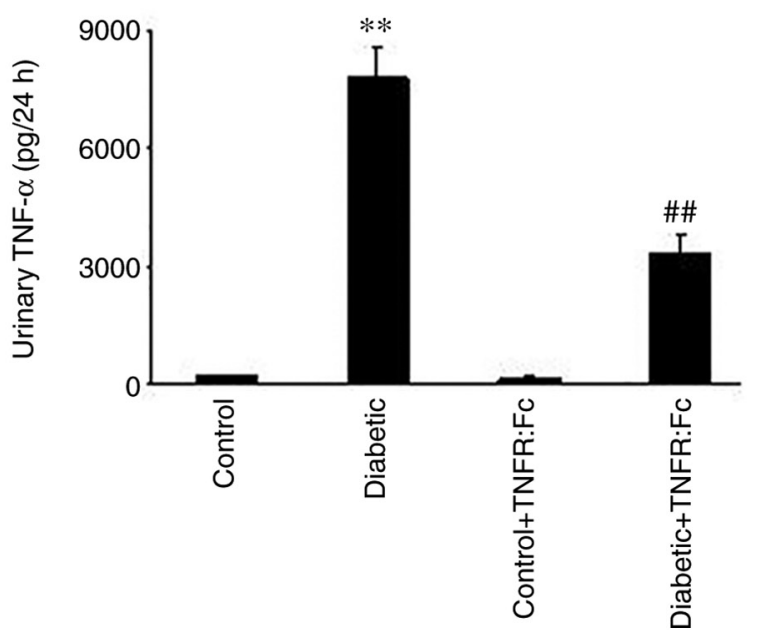

B
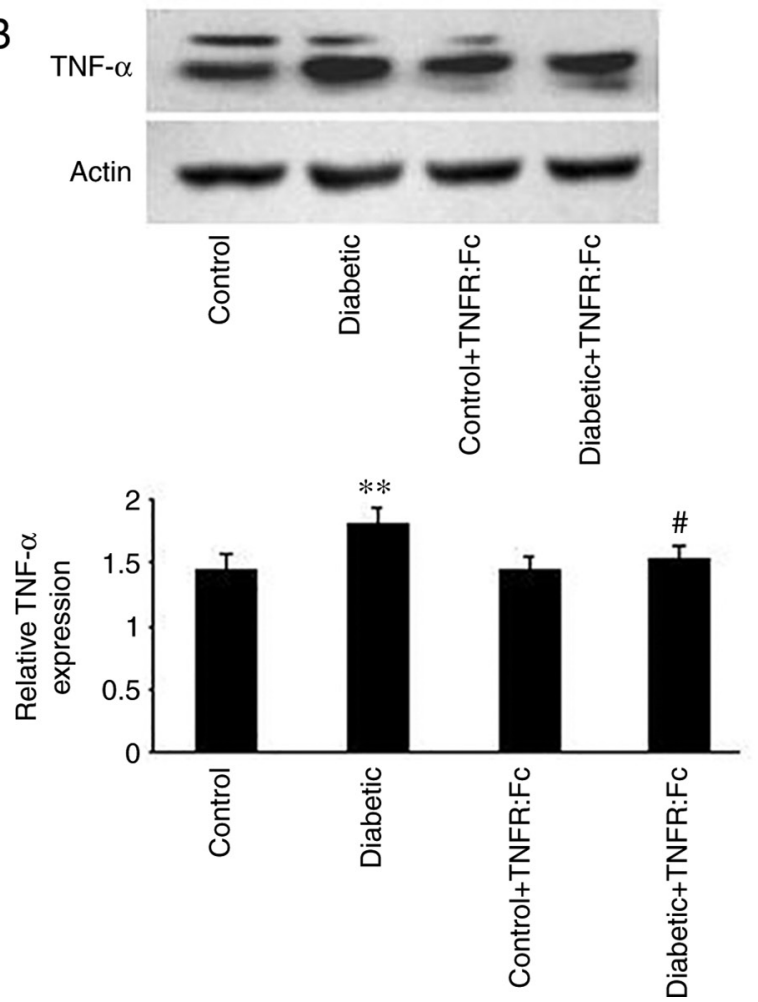

Figure 1. Changes in urinary TNF- $\alpha$ excretion and TNF- $\alpha$ protein expression in the TAL during diabetes. (A) Urinary TNF- $\alpha$ excretion. (B) TNF- $\alpha$ protein expression in the TAL. ${ }^{* *} \mathrm{P}<0.01$ vs. control group; ${ }^{\#} \mathrm{P}<0.05$ and ${ }^{\#} \mathrm{P}<0.01$ vs. diabetic group. TAL, thick ascending limb; TNFR:Fc, TNF receptor fusion protein.

Melittin treatment. After patching and recording the current of the $\mathrm{K}^{+}$channel for 2-3 min, melittin $(5 \mu \mathrm{M})$ was added and the current of the $\mathrm{K}^{+}$channel was recorded for 3-5 min.

Statistical analysis. Statistical analysis was performed using SPSS software version 19.0 (IBM Corp.). Data were presented as the mean \pm standard error of the mean and analyzed using a one-way ANOVA followed by a Tukey's post hoc test and Student-Newman-Keuls post hoc test. $\mathrm{P}<0.05$ was considered to indicate a statistically significant difference.

\section{Results}

Changes in urinary TNF- $\alpha$ excretion and TNF- $\alpha$ protein expression in the TAL during diabetes. To observe the changes in TNF- $\alpha$ levels during diabetes, urinary TNF- $\alpha$ excretion and TNF- $\alpha$ protein expression in the TAL were measured. The results demonstrated that urinary TNF- $\alpha$ excretion in diabetic rats was markedly increased compared with the control rats, and decreased following treatment with TNFR:Fc in the diabetic + TNFR:Fc group ( $n=7 ; \mathrm{P}<0.01 ;$ Fig. 1A). Furthermore, relative TNF- $\alpha$ expression (Fig. 1B) was significantly higher in the diabetic group compared with the control group $(n=5$; $\mathrm{P}<0.01$ ), while treatment with TNFR:Fc decreased its level in diabetic + TNFR:Fc rats $(n=5 ; P<0.05)$. These results confirm that TNF- $\alpha$ expression is upregulated during diabetes.

Changes in blood glucose, UAlb and urine output during diabetes. Compared with the control rats, the levels of blood glucose, UAlb and urine output in diabetic rats were significantly increased $(n=7 ; \mathrm{P}<0.01$; Table I). Compared with the diabetic rats, UAlb levels in the diabetic + TNFR:Fc group were markedly decreased $(n=7 ; P<0.01$; Table I), while no significant changes were observed in blood glucose and urine output levels following treatment with TNFR:Fc in the diabetic + TNFR:Fc group.

Effect of TNF- $\alpha$ on the basolateral Kir4.1/Kir5.1 channels in the TAL during diabetes. Increasing evidence has suggested that basolateral Kir4.1/Kir5.1 channels in the TAL play an important role in determining NKCC2 activity and influencing tubular $\mathrm{NaCl}$ transportation and urine concentration (10). Thus, Kir4.1/Kir5.1 protein expression was detected in each group via western blotting to investigate the effect of TNF- $\alpha$ on the basolateral $\mathrm{K}^{+}$channel in the TAL during diabetes. As presented in Fig. 2, relative Kir4.1/Kir5.1 protein expression was significantly decreased in diabetic rats compared with normal rats $(\mathrm{n}=5 ; \mathrm{P}<0.01)$, and increased in the diabetic + TNFR:Fc group following treatment with TNFR:Fc $(n=5$; $\mathrm{P}<0.01)$. Taken together, these results suggest that TNF- $\alpha$ inhibits the activity of basolateral Kir4.1/Kir5.1 in the TAL during diabetes.

Role of the PLA $A_{2}$-dependent pathway in the inhibitory effect of TNF- $\alpha$ on Kir4.1/Kir5.1 during diabetes. After revealing the inhibitory effect of TNF- $\alpha$ on Kir4.1/Kir5.1 during diabetes, the present study aimed to determine its underlying molecular mechanism. Previous studies have reported that the activity of the basolateral $\mathrm{K}^{+}$channel is often mediated by the $\mathrm{PLA}_{2}$-dependent pathway (12). Thus, the role of the $\mathrm{PLA}_{2}$-dependent pathway in the inhibitory effect of TNF- $\alpha$ on Kir4.1/Kir5.1 during diabetes was investigated. As presented 
Table I. Changes in blood glucose, UAlb and urine output during diabetes.

\begin{tabular}{lccc}
\hline Group & Blood glucose, mmol/1 & UAlb, mg/24 h & Urine output, ml/24 h \\
\hline Control & $5.31 \pm 0.45$ & $0.29 \pm 0.04$ & $9.12 \pm 1.33$ \\
Diabetic & $25.47 \pm 3.09^{\mathrm{a}}$ & $1.17 \pm 0.25^{\mathrm{a}}$ & $166.75 \pm 13.40^{\mathrm{a}}$ \\
Control + TNFR:Fc & $5.39 \pm 0.82$ & $0.31 \pm 0.06$ & $8.96 \pm 1.28$ \\
Diabetic + TNFR:Fc & $25.39 \pm 2.98$ & $0.58 \pm 0.07^{\mathrm{b}}$ & $143.25 \pm 21.82$
\end{tabular}

${ }^{\mathrm{a}} \mathrm{P}<0.01$ vs. control group; ${ }^{\mathrm{b}} \mathrm{P}<0.01$ vs. diabetic group. Data are presented as the mean \pm standard error of the mean. UAlb, urinary albumin; TNFR:Fc, TNF receptor fusion protein.
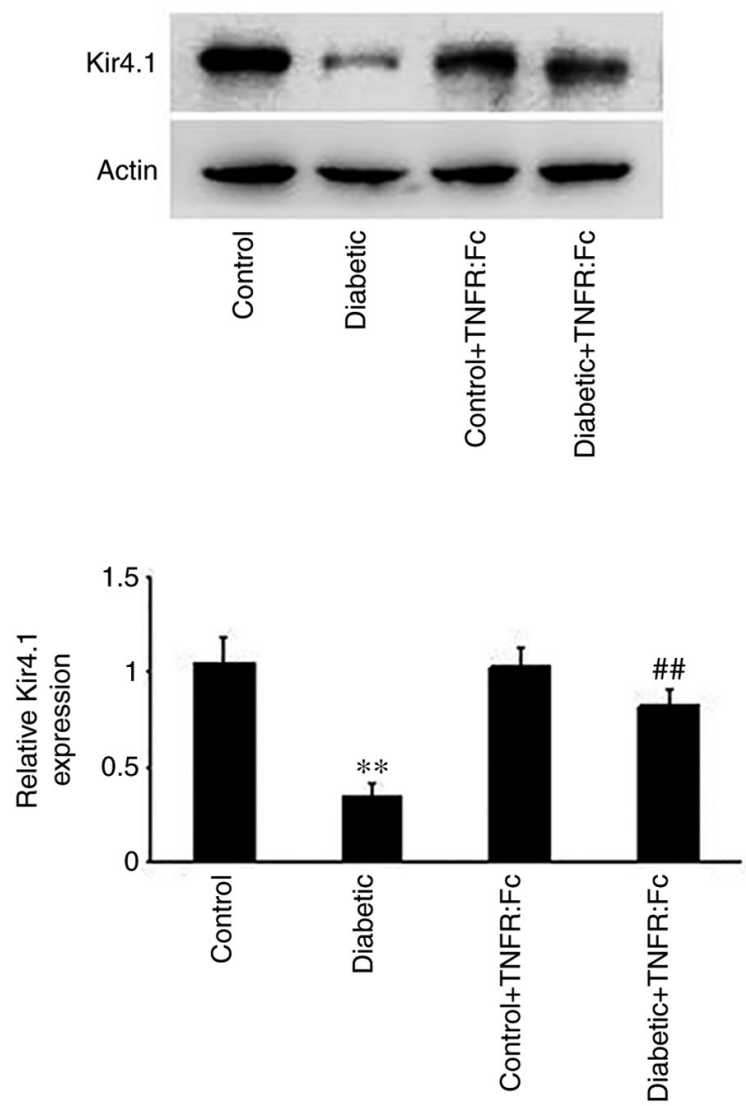
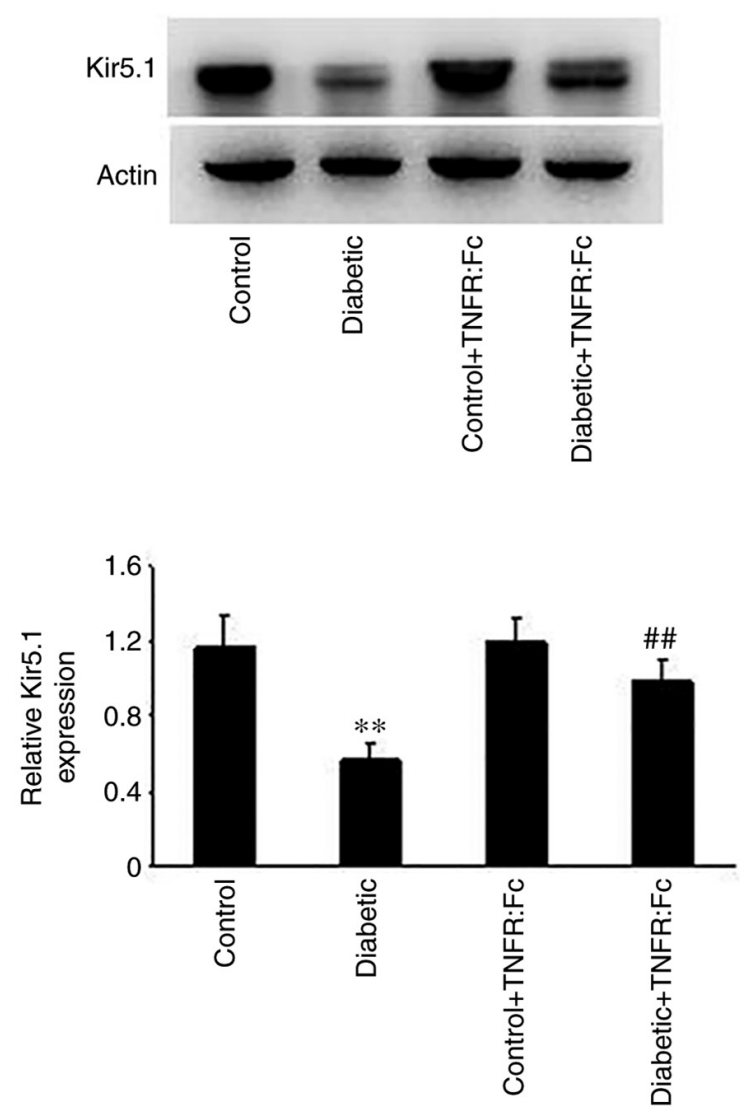

Figure 2. Effect of TNF- $\alpha$ on the basolateral Kir4.1/Kir5.1 channels in the thick ascending limb during diabetes. ${ }^{* *} \mathrm{P}<0.01 \mathrm{vs}$. control group; ${ }^{\# \#} \mathrm{P}<0.01 \mathrm{vs.} \mathrm{diabetic}$ group. TNFR:Fc, TNF receptor fusion protein; Kir, inwardly rectifying potassium channels.

in Fig. 3, relative PLA 2 expression was significantly higher in diabetic rats compared with normal rats $(\mathrm{n}=5 ; \mathrm{P}<0.01)$, but decreased in the diabetic + TNFR:Fc group compared with diabetic rats following treatment with TNFR:Fc $(n=5$; $\mathrm{P}<0.05)$. Thus, the $\mathrm{PLA}_{2}$-dependent pathway may participate in the regulatory effect of TNF- $\alpha$ on Kir4.1/Kir5.1 during diabetes. To further determine the role of the $\mathrm{PLA}_{2}$-dependent pathway, the effect of melittin, an agonist of $\mathrm{PLA}_{2}$ (17), on Kir4.1/Kir5.1 in the TAL was investigated via the patch clamp technique. The results demonstrated that addition of melittin $(5 \mu \mathrm{M})$ decreased the channel activity $\left(N P_{\mathrm{o}}\right)$ from $0.33 \pm 0.07$ to $0.08 \pm 0.02$ in a cell-attached patch $(n=5 ; P<0.01$, Fig. 4$)$. Collectively, these results suggest that the inhibitory effect of TNF- $\alpha$ on Kir4.1/Kir5.1 during diabetes is mediated by the $\mathrm{PLA}_{2}$-dependent pathway.
Role of the cyclooxygenase- ${ }_{2}\left(\mathrm{COX}_{2}\right) / P G E_{2}$ pathway in the inhibitory effect of TNF- $\alpha$ on Kir4.1/Kir5.1 during diabetes. As a downstream pathway of the $\mathrm{PLA}_{2}$-dependent pathway, the $\mathrm{COX}_{2} / \mathrm{PGE}_{2}$ pathway is associated with the development of diabetes (18). However, whether it is involved in the regulation of TNF- $\alpha$ on Kir4.1/Kir5.1 during diabetes remains unclear. Thus, the role of the $\mathrm{COX}_{2} / \mathrm{PGE}_{2}$ pathway in the inhibitory effect of TNF- $\alpha$ on Kir4.1/Kir5.1 during diabetes was also investigated in the present study. Western blot analysis was performed to detect $\mathrm{COX}_{2}$ protein expression in the TAL. As presented in Fig. 5A, relative $\mathrm{COX}_{2}$ protein expression was significantly higher in diabetic rats compared with normal rats $(\mathrm{n}=5 ; \mathrm{P}<0.01)$, but decreased in the diabetic + TNFR:Fc group compared with diabetic rats following treatment with TNFR:Fc ( $\mathrm{n}=5 ; \mathrm{P}<0.05)$. Subsequently, $\mathrm{PGE}_{2}$ expression was 

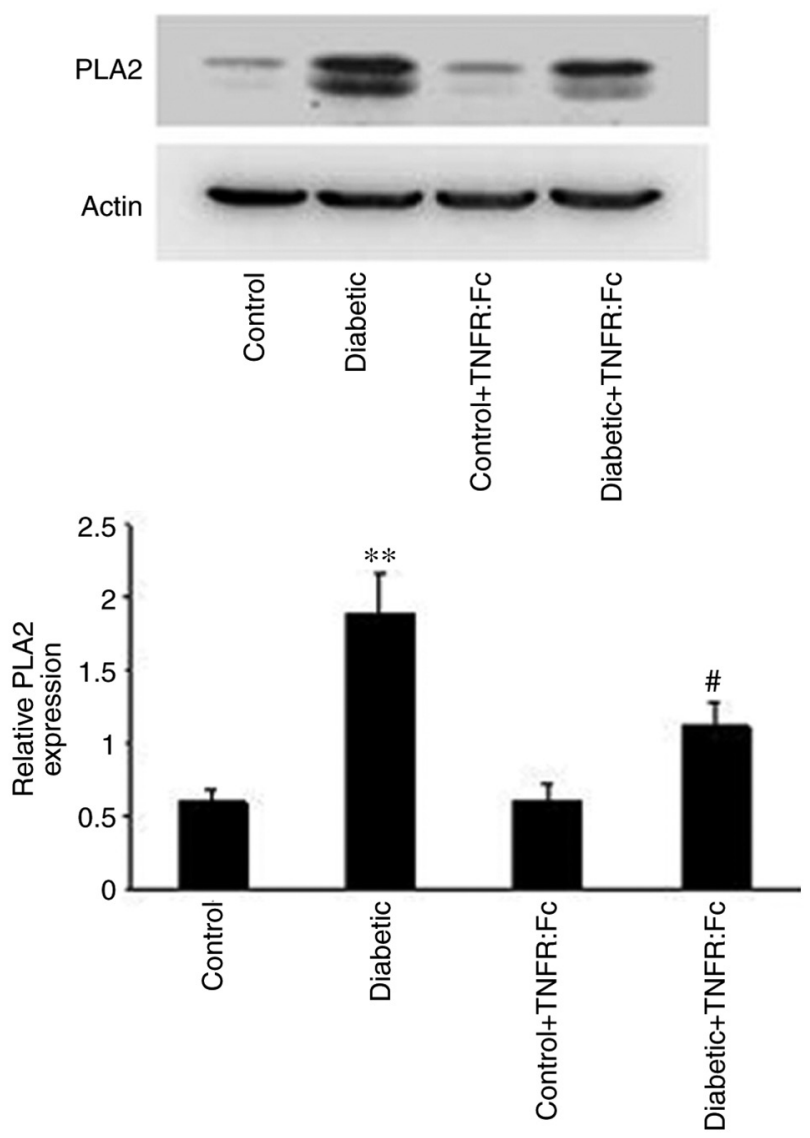

Figure 3. Change in protein expression of $\mathrm{PLA}_{2}$ in the thick ascending limb during diabetes. ${ }^{* *} \mathrm{P}<0.01$ vs. control group; ${ }^{~} \mathrm{P}<0.05$ vs. diabetic group. TNFR:Fc, TNF receptor fusion protein; $\mathrm{PLA}_{2}$, phospholipase $\mathrm{A}_{2}$.

measured in the TAL via ELISA. As presented in Fig. 5B, $\mathrm{PGE}_{2}$ expression was markedly increased in diabetic rats compared with normal rats, while treatment with TNFR:Fc decreased $\mathrm{PGE}_{2}$ expression in the diabetic + TNFR:Fc group $(\mathrm{n}=5 ; \mathrm{P}<0.01)$. The patch clamp technique was performed to determine the effect of $\mathrm{PGE}_{2}$ on Kir4.1/Kir5.1 during diabetes. The results demonstrated that the $N P_{\text {o }}$ decreased from $0.31 \pm 0.06$ to $0.09 \pm 0.03$ following treatment with $10 \mu \mathrm{M} \mathrm{PGE}_{2}$ $(\mathrm{n}=5 ; \mathrm{P}<0.01 ;$ Fig. 6$)$. Taken together, these results suggest that the $\mathrm{COX}_{2} / \mathrm{PGE}_{2}$ pathway is involved in the inhibitory effect of TNF- $\alpha$ on Kir4.1/Kir5.1 during diabetes.

\section{Discussion}

The present study aimed to investigate the effect of TNF- $\alpha$, elevated by diabetes, on the Kir4.1/Kir5.1 in the TAL. The results demonstrated that TNF- $\alpha$ inhibited the activity of Kir4.1/Kir5.1 via the $\mathrm{PLA}_{2} / \mathrm{COX} / \mathrm{PGE}_{2}$ pathway during diabetes. Currently, three lines of evidence support this concept. First, TNF- $\alpha$ expression in the TAL was significantly increased in diabetic rats, and decreased following treatment with TNFR:Fc. Secondly, the protein expression levels of $\mathrm{PLA}_{2}$ and $\mathrm{COX}_{2}$ were higher in the TAL of diabetic rats, and were decreased following treatment with TNFR:Fc. Thirdly, addition of melittin or $\mathrm{PGE}_{2}$ inhibited the channel activity of Kir4.1/Kir5.1 in a cell-attached patch. Thus, it was hypothesized that increased TNF- $\alpha$ expression during diabetes activates the $\mathrm{PLA}_{2} / \mathrm{COX}_{2} / \mathrm{PGE}_{2}$ pathway, thereby inhibiting basolateral Kir4.1/Kir5.1 channel activity in the TAL.

The $\mathrm{Na}^{+}$and $\mathrm{Cl}^{-}$load filtered from the glomerulus is reabsorbed in the TAL via two steps: First, they enter epithelial cells via apical NKCC2 and then, they leave the cells via basolateral $\mathrm{Na}^{-} \mathrm{K}^{+}$pump and $\mathrm{Cl}^{-}$channels, respectively (19). It is well-known that basolateral $\mathrm{K}^{+}$channels play an important role in the modulation of $\mathrm{NaCl}$ transportation by affecting cell membrane potential under physiological conditions (20). Activation of basolateral $\mathrm{K}^{+}$channels increases the negativity of the cell membrane potential, thereby augmenting the driving force for $\mathrm{Cl}^{-}$exit, while inhibition of basolateral $\mathrm{K}^{+}$channel activity depolarizes the cell membrane potential, thereby diminishing the driving force for the diffusion of $\mathrm{Cl}^{-}$across the basolateral membrane (21). Consequently, inhibition of $\mathrm{Cl}^{-}$diffusion leads to an increase in intracellular $\mathrm{Cl}^{-}$concentration, which suppresses the interaction between WNK lysine deficient protein kinase 3 and serine/threonine kinase 39, and inhibits NKCC2 activity by decreasing the phosphorylation of NKCC2 (22). Given that the active reabsorption of $\mathrm{NaCl}$ in the water-impermeable TAL is essential for the urinary concentrating mechanism, inhibition of $\mathrm{NaCl}$ reabsorption in the TAL under pathological conditions decreases the urinary concentrating ability (13). It has been reported that diabetic nephropathy impairs urinary concentrating ability (23).

DN is considered a form of 'microinflammation', whereby several cytokines are involved in its underlying immunopathological mechanisms (24). Among these, TNF- $\alpha$ is an important mediator of inflammatory tissue damage and a major participant in the pathogenesis of DN (25). Consistent with experimental models, clinical investigations have reported that serum and urinary concentrations of TNF- $\alpha$ in diabetic patients with nephropathy are higher than non-diabetic subjects or diabetic patients without renal involvement (16). Enhanced TNF- $\alpha$ is cytotoxic to renal cells and can cause direct renal injury by promoting inflammation and the accumulation of extracellular matrix, decreasing glomerular blood flow, inducing apoptosis and damaging glomerular permeability barrier $(26,27)$. TNF- $\alpha$ can also indirectly disrupt the barrier function of the glomerular capillary wall and enhance the albumin permeability by inducing the production of reactive oxygen species in diverse cells, including mesangial cells (28). In addition, Battula et al (29) demonstrated that increased TNF- $\alpha$ production in response to hypercalcemia inhibits $\mathrm{NKCC} 2$ activity and $\mathrm{NaCl}$ reabsorption via the $\mathrm{COX}_{2} / \mathrm{PGE}_{2}$ pathway, which contributes to polyuria and concentration defects.

There is a distinct association between $\mathrm{PLA}_{2}$ and the COX-PG system (30). PLA ${ }_{2}$ enzymes are the upstream regulators of liberating free arachidonic acid from the sn-2 position of membrane phospholipids $(31,32)$. Arachidonic acid is released from phospholipids via the action of $\mathrm{PLA}_{2}$ and converted into PGs via COXs (33). $\mathrm{PGE}_{2}$ is a prominent prostanoid produced in the kidney, which is involved in diverse renal functions regulating hemodynamics and tubular salt and water transport (34). COXs, including $\mathrm{COX}_{-1}$ and $\mathrm{COX}_{-2}$, are rate-limiting enzymes in the $\mathrm{PGE}_{2}$ synthesis pathway (35). While no major renal pathology has been reported for $\mathrm{COX}_{-1}$ knockout mice, $\mathrm{COX}_{2}$-lacking mice display abnormalities in renal development and severe nephropathy $(36,37)$. Previous studies have reported that renal $\mathrm{COX}_{-}$activity and $\mathrm{PGE}_{2}$ production are 

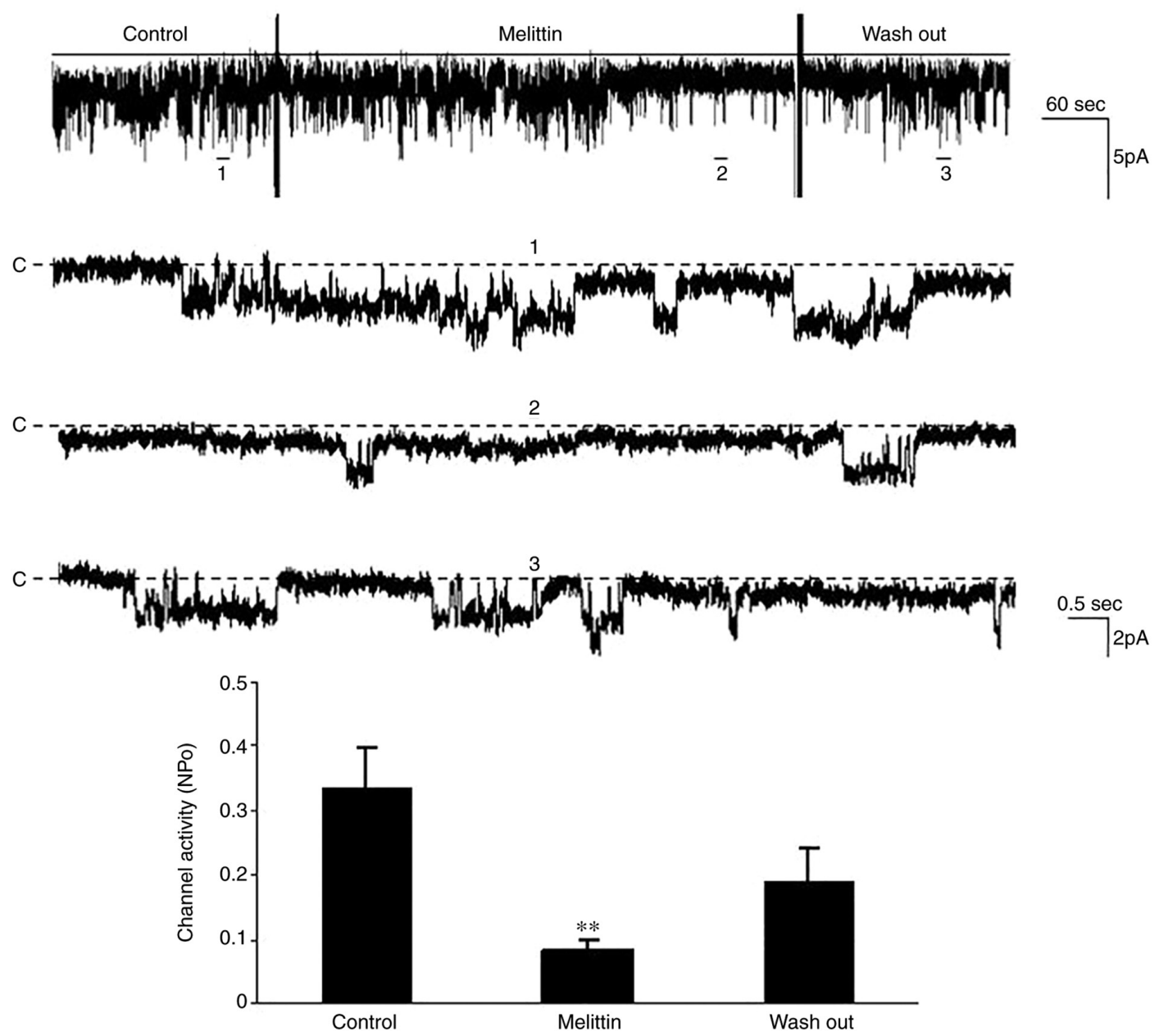

Figure 4. Effect of $5 \mu \mathrm{M}$ melittin on the Kir4.1/Kir5.1 channel activity. The experiment was recorded using a cell-attached patch clamp. The top trace represents the experimental time course. The other traces with numbers represent the fast time resolution. The holding potential was $0 \mathrm{mV}$, and the channel closed current is indicated by ' $\mathrm{C}$ '. ${ }^{* *} \mathrm{P}<0.01$ vs. control group. NPo, channel number and open probability; Kir, inwardly rectifying potassium channels.
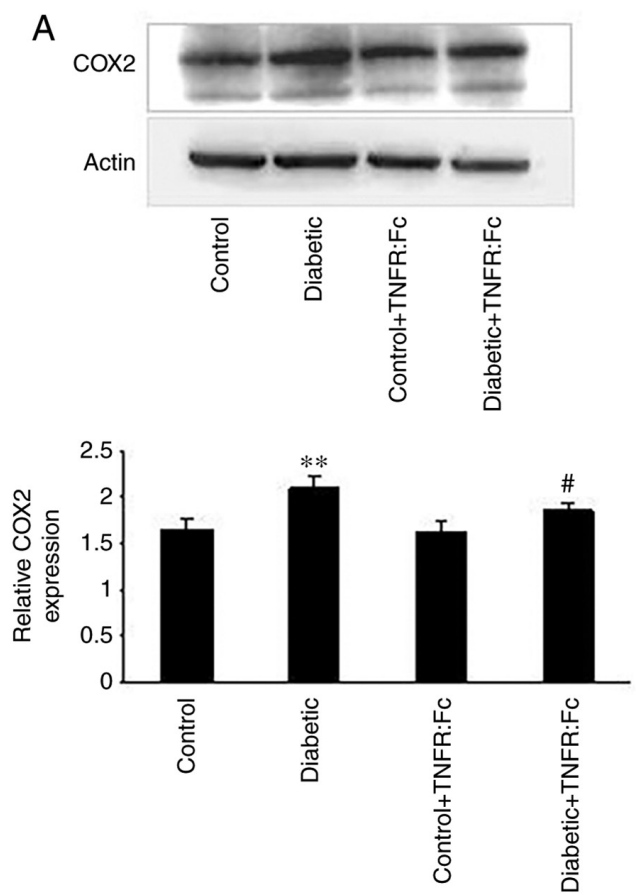

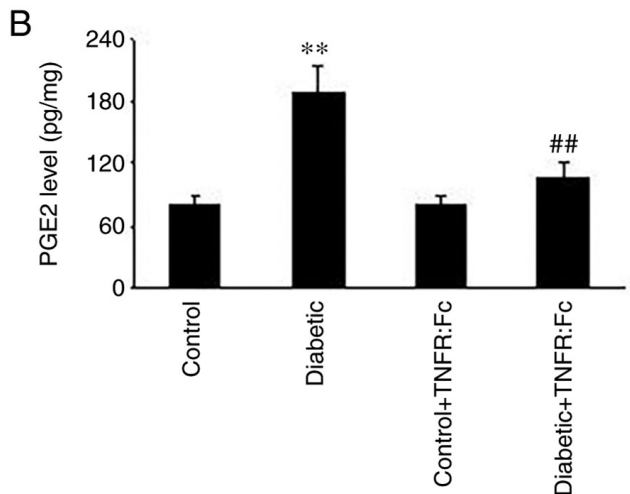

Figure 5. Changes in protein expression of $\mathrm{COX}_{2}$ and $\mathrm{PGE}_{2}$ level in the TAL during diabetes. (A) Protein expression of $\mathrm{COX}_{2}$ in the TAL. (B) PGE 2 level in the TAL. ${ }^{* * *} \mathrm{P}<0.01$ vs. control group; ${ }^{*} \mathrm{P}<0.05$ and ${ }^{\# \#} \mathrm{P}<0.01$ vs. diabetic group. $\mathrm{COX}_{2}$, cyclooxygenase- 2 ; $\mathrm{PGE}_{2}$, prostaglandin $\mathrm{E}_{2}$; TAL, thick ascending limb; TNFR:Fc, TNF receptor fusion protein. 


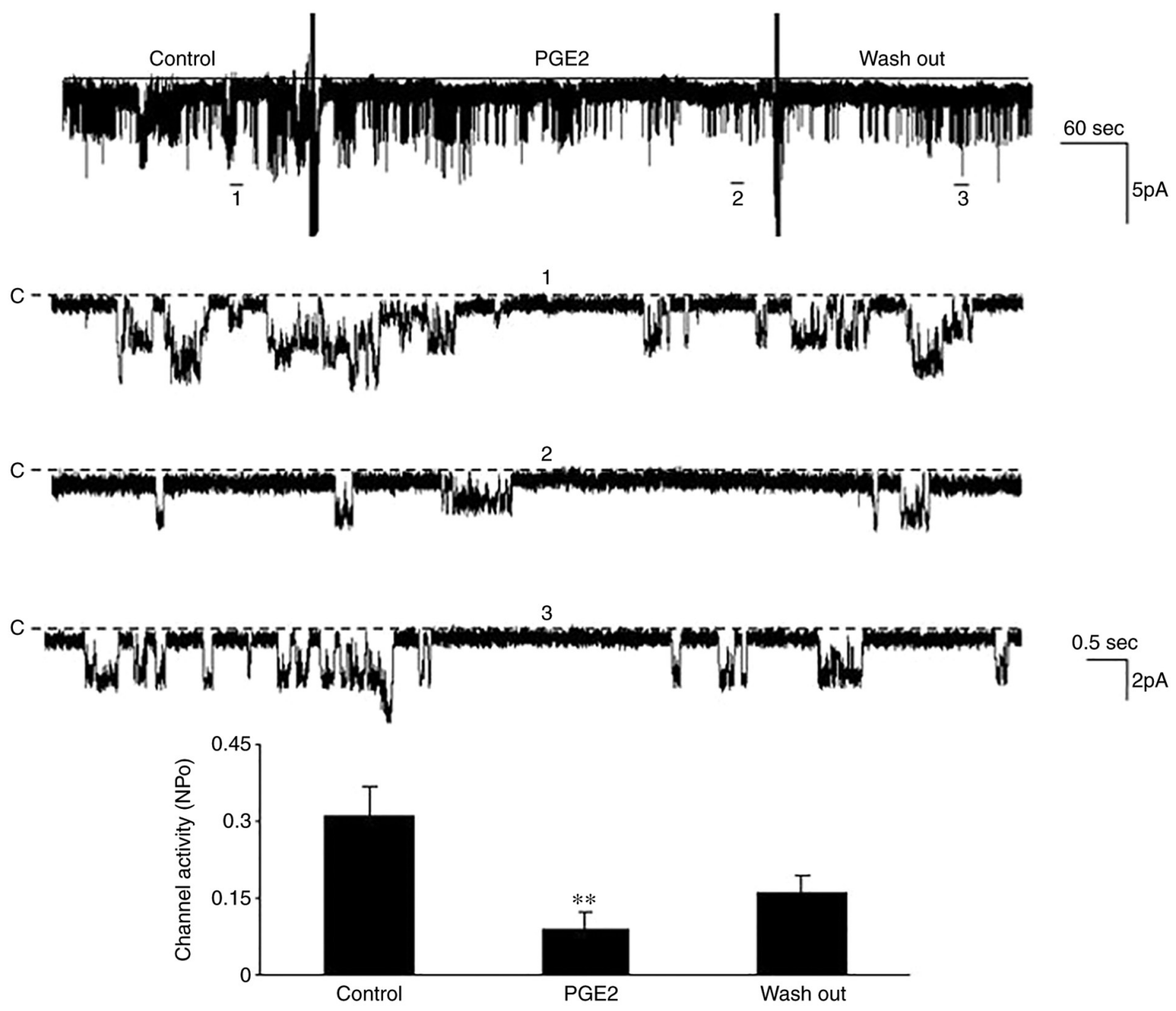

Figure 6. Effect of $10 \mu \mathrm{M} \mathrm{PGE}_{2}$ on the Kir4.1/Kir5.1 channel activity. The experiment was recorded by a cell-attached patch clamp. The top trace represents the experimental time course. The other traces with numbers represent the fast time resolution. The holding potential was $0 \mathrm{mV}$, and the channel closed current is indicated by ' $\mathrm{C}$ ' ${ }^{* *} \mathrm{P}<0.01$ vs. control group. $\mathrm{NPo}$, channel number and open probability; $\mathrm{PGE}_{2}$, prostaglandin $\mathrm{E}_{2}$; Kir, inwardly rectifying potassium channels.

elevated in diabetes mellitus, which contributes to the pathogenesis of $\mathrm{DN}$ (38). Inhibition of $\mathrm{COX}_{-2}$ has been demonstrated to reverse some of the renal complications of STZ-diabetes, such as attenuating glomerulosclerosis and glomerular hypertrophy, thereby slowing the development of proteinuria $(36,39)$.

The results of the present study and previous findings suggest that the $\mathrm{COX}_{2} / \mathrm{PGE}_{2}$ pathway is involved in the pathogenesis of diabetic nephropathy and the impairment of urinary concentrating ability; however, its underlying molecular mechanisms remain unclear. The findings of the current study demonstrated that the inhibitory effect of TNF- $\alpha$ on the basolateral Kir4.1/Kir5.1 channels in the TAL during diabetes occurred via regulation of the $\mathrm{PLA}_{2} / \mathrm{COX}_{2} / \mathrm{PGE}_{2}$ pathway. Given that the basolateral $\mathrm{K}^{+}$channels determine the driving force for $\mathrm{Cl}^{-}$diffusion across the basolateral membrane (23), a TNF- $\alpha$-induced decrease in channel activity of Kir4.1/Kir5.1 during diabetes may be associated with a decrease in $\mathrm{NaCl}$ reabsorption in the TAL and urine concentration. Thus, the results presented in the present study provide a novel mechanism by which TNF- $\alpha$ impairs urinary concentrating ability during diabetes, which occurs via stimulation of the $\mathrm{PLA}_{2} /$ $\mathrm{COX}_{2} / \mathrm{PGE}_{2}$ pathway to inhibit the activity of the basolateral Kir4.1/Kir5.1 channels in the TAL.
Only some pathological changes in early stage of diabetic nephropathy were observed in the present study, others in middle or late stages of diabetic nephropathy will be done in the future study in order to comprehensively explore the pathogenesis of diabetes and find effective prevention and treatment methods.

\section{Acknowledgements}

The authors would like to thank Dr Jiaqi Wang (Statistics Department at the Public Health College of Jiamusi University) for providing constructive suggestions on the statistical analysis in the manuscript.

\section{Funding}

This work was supported by the Chinese National Nature Science Foundation (grant no. 31400994), Heilongjiang Natural Science Foundation (grant no. LH2019C065), Heilongjiang Provincial Department of Health Project (grant no. 2018104), National Basic Medical Science Team Project (grant no. JDXKTD-2019002) and North Medicine and Functional Food Characteristic Construction Project. 


\section{Availability of data and materials}

All data generated or analyzed during this study are included in this published article.

\section{Authors' contributions}

GZ and ZL performed the experiments. YZ and RC acquired and analyzed data. XZ and WW analyzed data and drafted the manuscript. HS designed the project and revised the manuscript. All authors have read and approved the final manuscript. GZ and HS confirm the authenticity of all the raw data.

\section{Ethics approval and consent to participate}

The present study was approved by the Medical Ethics Committee of Jiamusi University (Jiamusi, China; approval no. JMSU-229).

\section{Patient consent for publication}

Not applicable.

\section{Competing interests}

The authors declare that they have no competing interests.

\section{References}

1. Jenny L, Melmer A, Laimer M, Hardy ET, Lam WA and Schroeder V: Diabetes affects endotelial cell function and alters fibrin clot formation in a microvascular flow model: A pilot study. Diab Vasc Dis Res: Feb 10, 2020 (Epub ahead of print).

2. Iwai T, Miyazaki M, Yamada G, Nakayama M, Yamamoto T, Satoh M, Sato H and Ito S: Diabetes mellitus as a cause or comorbidity of chronic kidney disease and its outcomes: The Gonryo study. Clin Exp Nephrol 22: 328-336, 2018.

3. Kanwar YS, Sun L, Xie P, Liu FY and Chen S: A glimpse of various pathogenetic mechanisms of diabetic nephropathy. Annu Rev Pathol 6: 395-423, 2011.

4. Kashihara N, Haruna Y, Kondeti VK and Kanwar YS: Oxidative stress in diabetic nephropathy. Curr Med Chem 17: 4256-4269, 2010.

5. Mora $C$ and Navarro J: Inflammation and pathogenesis of diabetic nephropathy. Metabolism 53: 265-266, 2004.

6. Wada $J$ and Makino H: Inflammation and the pathogenesis of diabetic nephropathy. Clin Sci 124: 139-152, 2013.

7. Zhang B, Ramesh G, Norbury CC and Reeves WB: Cisplatininduced nephrotoxicity is mediated by tumor necrosis factor-alpha produced by renal parenchymal cells. Kidney Int 72: 37-44, 2007.

8. Kalantarinia K, Awad AS and Siragy HM: Urinary and renal interstitial concentrations of TNF- $\alpha$ increase prior to rise in albuminuria in diabetic rats. Kidney Int 64: 1208-1213, 2003.

9. Navarro J, Milena FJ, Mora C, León C, Claverie F, Flores C and García J: Tumor necrosis factor-alpha gene expression in diabetic nephropathy: Relationship with urinary albumin excretion and effect of angiotensin-converting enzyme inhibition. Kidney Int Suppl 68: S98-S102, 2005.

10. Kong S, Zhang C, Li W, Wang L, Luan H, Wang WH and Gu R: Stimulation of $\mathrm{Ca}^{2+}$-sensing receptor inhibits the basolateral 50-pS K channels in the thick ascending limb of rat kidney. Biochim Biophys Acta 1823: 273-281, 2012.

11. Hebert SC: Roles of $\mathrm{Na}-\mathrm{K}-2 \mathrm{Cl}$ and $\mathrm{Na}-\mathrm{Cl}$ cotransporters and ROMK potassium channels in urinary concentrating mechanism. Am J Physiol 275: F325-F327, 1998.

12. Wang M, Sui H, Li W, Wang J, Liu Y, Gu L, Wang WH and Gu R: Stimulation of $\left.\mathrm{A}_{2 \mathrm{a}}\right)$ adenosine receptor abolishes the inhibitory effect of arachidonic acid on the basolateral 50-pS K channel in the thick ascending limb. Am J Physiol Renal Physiol 300: F906-F913, 2011.
13. Hebert SC, Desir G, Giebisch G and Wang W: Molecular diversity and regulation of renal potassium channels. Physiol Rev 85: 319-371, 2005.

14. Zhang C, Wang L, Su X, Lin DH and Wang WH: KCNJ10 (Kir4.1) is expressed in the basolateral membrane of the cortical thick ascending limb. Am J Physiol Renal Physiol 308: F1288-F1296, 2015.

15. Fan L, Wang X, Zhang D, Duan X, Zhao C, Zu M, Meng X, Zhang C, Su XT, Wang MX, et al: Vasopressin-induced stimulation of the $\mathrm{Na}(+)$-activated $\mathrm{K}(+)$ channels is responsible for maintaining the basolateral $\mathrm{K}(+)$ conductance of the thick ascending limb (TAL) in EAST/SeSAME syndrome. Biochim Biophys Acta 1852: 2554-2562, 2015.

16. Dipetrillo K, Coutermarsh B and Gesek FA: Urinary tumor necrosis factor contributes to sodium retention and renal hypertrophy during diabetes. Am J Physiol Renal Physiol 284: F113-F121, 2003.

17. Ling BN, Webster CL and Eaton DC: Eicosanoids modulate apical $\mathrm{Ca}(2+)$-dependent $\mathrm{K}^{+}$channels in cultured rabbit principal cells. Am J Physiol 263: F116-F126, 1992.

18. Mouchlis VD and Dennis EA: Phospholipase $A_{2}$ catalysis and lipid mediator lipidomics. Biochim Biophys Acta Mol Cell Biol Lipids 1864: 766-771, 2019.

19. Zhang G, Gui S, Wang W, Meng D, Meng Q, Luan H, Zhao R, Zhang $\mathrm{J}$ and Sui $\mathrm{H}$ : Acute stimulatory effect of tumor necrosis factor on the basolateral $50 \mathrm{pS} \mathrm{K}$ channels in the thick ascending limb of the rat kidney. Mol Med Rep 18: 4733-4738, 2018.

20. Paulais M, Lourdel S and Teulon J: Properties of an inwardly rectifying $\mathrm{K}(+)$ channel in the basolateral membrane of mouse TAL. Am J Physiol Renal Physiol 282: F866-F876, 2002.

21. Wang W, Hebert SC and Giebisch G: Renal $\mathrm{K}^{+}$channels: Structure and function. Annu Rev Physiol 59: 413-436, 1997.

22. Ponce-Coria J, San Cristobal P, Kahle KT, Vazquez N, Pacheco-Alvarez D, de Los Heros P, Juárez P, Muñoz E, Michel G, Bobadilla NA, et al: Regulation of NKCC2 by a chloride-sensing mechanism involving the WNK3 and SPAK kinases. Proc Natl Acad Sci 105: 8458-8463, 2008.

23. Ma SZ, Du J and Ma LR: The change of urinary osmolalities and plasma osmolalities in diabetic rats induced by STZ. Chin Lab Diagn 12: 976-978, 2008.

24. Zhang Y, Liu T, Chen Y, Dong Z, Zhang J, Sun Y, Jin B, Gao F, Guo S and Zhuang R: CD226 reduces endothelial cell glucose uptake under hyperglycemic conditions with inflammation in type 2 diabetes mellitus. Oncotarget 7: 12010-12023, 2016.

25. Darwish NM, Elnahas YM and Alqahtany FS: Diabetes induced renal complications by leukocyte activation of nuclear factor $\kappa-B$ and its regulated genes expression. Saudi J Biol Sci 28: 541-549, 2021.

26. Ortiz A, González-Cuadrado S, Bustos C, Alonso J, Gómez-Guerrero C, López-Armada MJ, González-Arana E, Plaza JJ and Egido J: Tumor necrosis factor as a mediator of glomerular damage. J Nephrol 8: 27-34, 1995.

27. Xu C, Chang A, Hack BK, Eadon MT, Alper SL and Cunningham PN: TNF-mediated damage to glomerular endothelium is an important determinant of acute kidney injury in sepsis. Kidney Int 85: 72-81, 2014.

28. Mccarthy E, Sharma R, Sharma M, Li JZ, Ge XL, Dileepan KN and Savin VJ: TNF-alpha increases albumin permeability of isolated rat glomeruli through the generation of superoxide. J Am Soc Nephrol 9: 433-438, 1998.

29. Battula S, Hao S, Pedraza PL, Stier CT and Ferreri NR: Tumor necrosis factor-alpha induces renal cyclooxygenase-2 expression in response to hypercalcemia. Prostaglandins Other Lipid Mediat 99: 45-50, 2012.

30. Nasrallah R, Hassouneh R and Hebert RL: $\mathrm{PGE}_{2}$, kidney disease, and cardiovascular risk: Beyond hypertension and diabetes. J Am Soc Nephrol 27: 666-676, 2016.

31. Murakami M, Nakatani Y, Atsumi GI, Inoue K and Kudo I: Regulatory functions of Phospholipase A2. Crit Rev Immunol 37: 127-195, 2017.

32. Murakami M and Kudo I: Phospholipase A2. J Biochem 131: 285-292, 2002.

33. Kudo I and Murakami M: Prostaglandin E synthase, a terminal enzyme for prostaglandin E2 biosynthesis. J Biochem Mol Biol 38: 633-638, 2005

34. Quilley J, Santos M and Pedraza P: Renal protective effect of chronic inhibition of COX-2 with SC-58236 in streptozotocin-diabetic rats. Am J Physiol Heart Circ Physiol 300: H2316-H2322, 2011.

35. Nasrallah R, Landry A, Singh S, Sklepowicz M and Hébert RL: Increased expression of cyclooxygenase- 1 and -2 in the diabetic rat renal medulla. Am J Physiol Renal Physiol 285: F1068-F1077, 2003. 
36. Langenbach R, Morham SG, Tiano HF, Loftin CD, Ghanayem BI, Chulada PC, Mahler JF, Lee CA, Goulding EH, Kluckman KD, et al: Prostaglandin synthase 1 gene disruption in mice reduces arachidonic acid-induced inflammation and indomethacin-induced gastric ulceration. Cell 83: 483-492, 1995.

37. Morham SG, Langenbach $\mathrm{R}$, Loftin $\mathrm{CD}$, Tiano HF, Vouloumanos N, Jennette JC, Mahler JF, Kluckman KD, Ledford A, Lee CA and Smithies O: Prostaglandin synthase 2 gene disruption causes severe renal pathology in the mouse. Cell 83: 473-482, 1995.
38. Jia Z, Sun Y, Liu S, Liu Y and Yang T: COX-2 but not mPGES-1 contributes to renal PGE2 induction and diabetic proteinuria in mice with type-1 diabetes. PLoS One 9: e93182, 2014.

39. Komers R, Lindsley JN, Oyama TT and Anderson S: Cyclo-oxygenase-2 inhibition attenuates the progression of nephropathy in uninephrectomized diabetic rats. Clin Exp Pharmacol Physiol 34: 36-41, 2007. 